\title{
Fear of cancer recurrence in adolescent and young adult cancer survivors: a
}

\section{systematic review of the literature}

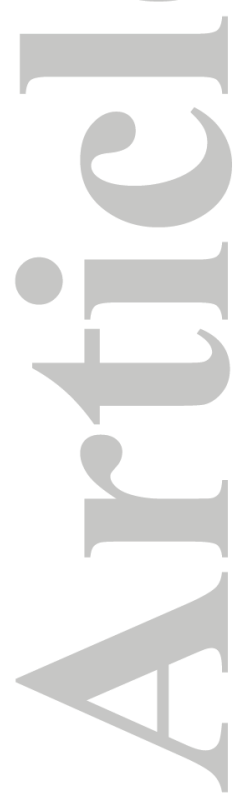

Running title: FCR in AYAs

\author{
Yuan Yang a.b \# \\ Wen Li ${ }^{b \#}$ \\ Yunhong Wen ${ }^{\mathrm{c} \#}$ \\ Hongmei Wang d\# \\ Hengwen Sun ${ }^{\mathrm{e}}$ \\ Weijiang Liang ${ }^{f}$ \\ Bin Zhang a
}

Gerry Humphris ${ }^{\mathrm{g} *}$

a Department of Psychiatry, Southern Medical University Nanfang Hospital, Guangzhou, Guangdong, 510515, China;

${ }^{b}$ Unit of Psychiatry, Faculty of Health Sciences, University of Macau, Macau SAR, China;

'Institute of Neuroscience, Newcastle University, Newcastle upon Tyne, NE2 4HH, UK;

${ }^{d}$ Department of Radiotherapy, Southern Medical University Nanfang Hospital, Guangzhou,

Guangdong, 510515, China;

e Department of Radiotherapy, Cancer Centre, Guangdong General Hospital, Guangzhou, Guangdong, 510080, China;

f Department of Oncology, Southern Medical University Nanfang Hospital, Guangzhou, Guangdong, 510515, China;

${ }^{\mathrm{g}}$ School of Medicine, University of St Andrews, North Haugh, St Andrews, Fife, UK.

\# These authors contributed equally to the work.

\section{Correspondence}

* Prof Gerry Humphris, School of Medicine, University of St Andrews, Medical and Biological Sciences

Building, North Haugh, St Andrews, Fife, KY16 9TF, UK. Email: gmh4@st-andrews.ac.uk

This article has been accepted for publication and undergone full peer review but has not been through the copyediting, typesetting, pagination and proofreading process which may lead to differences between this version and the Version of Record. Please cite this article as doi: 10.1002/pon.5013 


\section{Abstract}

Objective: The current systematic review aims to provide an overview of fear of cancer recurrence (FCR) in adolescent and young adult cancer survivors (15-39 yrs at cancer diagnosis, AYAs).

Methods: MEDLINE, PubMed, PsycINFO and Embase databases were independently searched to identify relevant quantitative articles. PRISMA systematic review procedures were followed with quality assessment.

Results: Seventeen studies were included in the current review. All were quantitative studies that utilized a cross-sectional study design. Seven articles reported results of FCR prevalence, six studied determinants related to FCR and eleven articles provided information about consequences of FCR. Prevalence of FCR ranged from 31\% to $85.2 \%$ among AYA survivors. Associations between sociodemographic/clinical variables and FCR were inconsistent. Psychological distress, and higher treatment intensity were positively associated with higher FCR levels. Lower scores on levels of physical, psychological functioning and overall healthrelated Quality of Life (QoL) were identified as consequences of increased FCR.

Conclusion: FCR appears to be a prevalent concern among adolescent and young adult cancer populations. Adequate assessment to determine need for support and intervention is still required. Longitudinal studies in AYAs are warranted to understand the development and potential influence of FCR. Age-appropriate and flexible psychological care would be more successful potentially with this crucial background information.

\section{Keywords:}

Adolescent, Cancer, Fear of recurrence, Oncology, Review, Survivor, Young adult Systematic review registration number: CRD42018112306

\section{Word count}

\section{Abstract: 205}

Full text (exclude reference): 5914

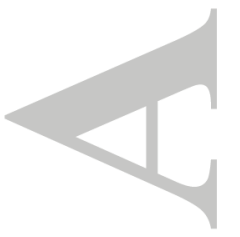

This article is protected by copyright. All rights reserved. 


\section{Introduction}

Many different labels have been utilized to describe fears about the spread or relapse of cancer, such as fear of recurrence/fear of cancer recurrence (FoR or FCR) [1], fear of progression (FoP) [2], or worry/concern about disease return [3] etc. However, researchers tend to believe that these descriptions are virtually comparable on a conceptual level $[2,4$, 5], and for practical purposes, there is indeed very strong overlap among them. In this review, the term FCR was used. FCR is commonly defined as: fear, worry, or concern relating to the possibility that cancer will come back or progress [6]. Patients with high FCR often report significant psychological distress (i.e. depression, anxiety), increased health service use $[7,8]$, as well as negative behavior changes (i.e. avoidance, excessive personal selfexamination behaviors) [9-12]. This concern may appear immediately after cancer diagnosis or treatment and has been shown to remain stable for years [13].

Recent studies have shown that about $24-40 \%$ of the survivors reported moderate to high levels of need for help dealing with their FCR [14-16]. Studies consistently reported that survivors diagnosed at a young age, female gender, and patients with more physical symptoms were more likely to experience higher FCR $[14,17]$. Meta-analysis showed that having had a mastectomy [4], radiotherapy [18] or chemotherapy [19] were significantly related to elevated fear level. A recent study indicated that psychological factors play a stronger role in FCR than demographic or clinical factors [20]. Lebel et al., found that a patient's FCR was significantly predicted by the individual's perceived risk of recurrence, illness uncertainty, and triggers [7]. Smith and colleagues indicated that negative metacognitive beliefs, as well as intrusive post-traumatic stress symptoms were independent correlates of FCR, which accounted for $26 \%$ and $28 \%$ of the total observed variance, respectively [21]. Another large sample study in Chinese cancer patients revealed that higher stress, anxiety, depressive symptom and personality (pessimism) were significant predictors of FCR, and hierarchical regression analysis showed that sociodemographic and clinical factors only accounted for $6.9 \%$ of the variance of FCR while psychological variables explained $33.1 \%$ of the total variance [22].

Many reviews have been conducted to provide overall knowledge about FCR in adult survivors. The first literature review on FCR was published in 1997 by Lee-Jones and 
colleagues [1]. Since the publication of the first review, FCR research has expanded considerably. In recent years, Crist et al. [23] performed a systematic review to identify key variables associated with FCR and eventually included 43 studies in the article. They reported the most consistent predictor of elevated FCR was younger age, and revealed that low optimism, family stressors as well as fewer significant others were additional important factors moderately associated with higher FCR. Simard and his colleagues [17] performed the most recent and robust review of quantitative studies in 2013 by searching more databases and identified 130 eligible articles. They concluded that younger age, psychological distress, and lower quality of life (QoL) were consistently associated with increased FCR, and family caregivers tended to report higher FCR than the patients. In the same year, Koch et al. [4] completed a systematic review in long-term cancer survivors (above 5 years since diagnosis). They reported that survivors suffered from FCR even years after initial cancer diagnosis, and studies including long-term and short-term survivors showed no significant change of FCR over time. In addition, reviews concentrating on specific cancer populations were also conducted. In 2015, a review by Ozga et al. [24] was published and it concluded that hopelessness, anxiety about death, uncertainty of the future, faith and more PTSD symptoms were significantly related to FCR in ovarian cancer survivors.

Even though these FCR literature reviews have been published since 1997, and previous research has consistently showed that young age was significantly associated with increased FCR, this relationship has only been observed in adult samples, and no review has focused specifically on how FCR manifests itself in adolescent and young adult (AYA) cancer survivors. However, cancer is the leading cause of disease-related death among AYAs [25], and recently national AYA programs have been attempted to fill the gap between the pediatric and adult oncology services and to provide better support for AYAs cancer patients [26]. We believe these features indicate an important need to conduct a specifically targeted systematic overview of FCR in adolescent and young adults.

There are different definitions of the AYAs among countries [26]. In a recent report WHO summarizes that adolescents and youth are referred to as young people, encompassing the ages of 10 to 19 years [27]. In the United States, adolescent and young adults are patients 
aged between 15 to 39 years at cancer diagnosis. However, in the UK, the spectrum of AYAs are patients aged between 13 to 24 years. Other countries, such as Netherlands, consider patients aged of 18 to 35 years at diagnosis as AYAs, while some other countries have not yet set a clear definition of it.

In the current review, we use the US definition of AYAs in order to include more eligible studies. It has been reported that around 70,000 AYAs are diagnosed with cancer every year in the US, which accounts for nearly $5 \%$ of the total cancer diagnoses in the country [28]. Research also reported that AYAs are more likely than either younger persons or older adults to be diagnosed with certain types of cancer, such as leukemia, testicular cancer, thyroid cancer and Hodgkin lymphoma, and the most common cancers in AYAs are: brain, breast, cervical and colorectal cancer [28]. However, the unique genetic and biological features of adolescent and young adult cancer patients were still unclear.

In all, the majority of existing studies on FCR has been performed with mixed-age samples or adult samples of breast cancer patients. It is still unclear how FCR behaves among AYA cancer survivors. This current review focuses on this special group of people aged between 15 to 39 years old at cancer diagnosis and aims to assess the prevalence, potential determinants (i.e. correlates or predictors) and consequences/outcomes of FCR among AYAs.

\section{Methods}

\section{Literature search}

MEDLINE, PubMed, PsycINFO and Embase databases were systematically and independently searched by two authors (HMW and WJL), from their inception until $1^{\text {st }}$ September 2018 , to identify relevant articles. No restrictions were placed on publication date. PRISMA systematic review procedures were followed including a quality assessment (the PRISMA checklist is presented in supplementary file 1) [29]. The systematic review was registered on PROSPERO on $11^{\text {th }}$ Oct 2018, and the registration number is: CRD42018112306.

The key search terms were: ("fear" [Mesh] or worry or concern), ("neoplasm" [Mesh] or cancer or carcinoma), ("recurrence" [Mesh] or progression or return or relapse), and ("adolescent" [Mesh] or teenager or teens or "young adult" [Mesh] or youngster or young or 
AYA). Searching was conducted using the 'OR' and 'AND' functions. The detailed strategy and search result of each database is outlined in supplementary file 2 . The references in identified articles were also screened manually for any additional relevant studies.

\section{Inclusion and exclusion criteria}

Studies were screened for eligibility before inclusion. According to the PICOS acronym, to be included in this review, references had to meet the following criteria: Participants $(P)$ : AYAs aged between 15 to 39 years at cancer diagnosis; Interventions (I): NA; Comparisons (C): NA; Outcomes $(O)$ : quantitative FCR results on prevalence, influencing factor, and consequence; Study Design (S): cross-sectional, longitudinal or RCT studies. Papers needed to be written in English and published in peer-reviewed journal. References were excluded if they were conference abstracts, editorials, commentaries, dissertations, review articles, or case studies. Studies using similar, however not accurate keywords such as 'fear of dying', 'fear of the future' or 'fear of the worst happening' were also excluded. Studies that compared FCR outcomes between AYA group and older adult group were included in the review, but only when FCR results of AYAs were reported. References were screened for eligibility by two authors (YY and YHW).

\section{Data extraction}

Titles and abstracts of potential eligible records were reviewed after removing duplicate studies, then unsuitable articles were excluded. Full papers were subsequently obtained and examined. Only papers that fulfilled the full inclusion criteria for the review were kept. For each study, the following data were extracted: 1) first author's name, 2) year of publication, 3) country of study, 4) study design, 5) basic sociodemographic and clinical/treatment information of the study sample (such as age at diagnosis and at survey, gender percentage, time since diagnosis), 6) FCR measurement, and 7) main findings of the study (i.e. FCR prevalence, potential determinants and outcomes). The independent variables of the original article were classified as the 'potential determinants', while the dependent variables were considered as the 'outcomes/consequences'. 


\section{Quality assessment}

The quality of each included article was assessed using the Standard Quality Assessment Criteria for quantitative studies (QualSyst criteria) [29]. Items were scored on the specific criteria (Yes $=2$, Partial $=1$, or No $=0$ ). Items not applicable to a particular study design were marked ' $N / A^{\prime}$ ' and were excluded from the calculation of the total quality score. A summary quality score was calculated for each study by summing the total score obtained across relevant items and dividing by the total possible score (i.e.: 28 -(number of 'N/A' $\times 2$ 2)). Strong quality was defined as $(>0.80)$, good quality $(0.70-0.80)$, adequate quality $(0.50-0.70)$, or limited quality $(<0.50)$ [29]. The quality assessment was conducted by two researchers independently (YY and YHW). In situations of disagreement of a study, another researcher (LW) repeated the assessment and in discussion reached consensus. Senior author (HWS) overviewed the procedures.

\section{Results}

\section{Study selection}

The search process is presented in Figure 1. The literature search of Pubmed, Embase, PsycINFO and MEDLINE databases identified 1004 references. After duplicates were excluded, 835 records remained. Examination of titles and abstracts for appropriateness left 58 articles. After retrieving full texts and further evaluation, 17 studies were included in the systematic review. All the included studies were assessed by the QualSyst criteria, and none were scored as limited quality. Detailed scores of quality assessment are showed in supplementary file 3.

\section{Characteristics of included studies}

The publication dates of the studies ranged from 1997 to 2018 (two articles were published in the 1990s [30,31], three in the 2000s [32-34], and the remaining articles were all published since 2010). Nine studies were conducted in the US, two each in Canada, Netherlands, and Germany, and one each in Sweden and Finland. Sample size varied from 20 to 1395 . Three studies concentrated specifically on AYA breast cancer survivors $[32,35,36]$, one focused on gynecological cancer [37], one on leukemia [30], eleven articles studied mixed AYA cancer populations, and one did not report cancer type [38]. 
Eleven studies reported both age at cancer diagnosis and age at survey, two studies only reported age at diagnosis $[26,36]$ and 4 only reported age at survey [31, 32, 35, 39]. As for FCR measurement, questionnaire(s) were frequently utilized (as opposed to standardized clinical interview). The number of scale items ranged from 1 to 30 , and only eight studies utilized a validated instrument, such as Cancer Worry Scale (CWS), Concerns About Recurrence Scale (CARS) and Fear of Progression Questionnaire-short form (FoP-SF). Four studies used a single FCR question $[25,31,32,40]$ and five used study-specific questions. In all, seven articles reported results of FCR prevalence, six of them studied determinants related to FCR and 11 articles provided information about consequences of FCR. Main characteristics and findings of the included articles are presented in Table 1.

\section{Prevalence of FCR}

Seven articles reported prevalence data on $\operatorname{FCR}[25,26,30,32,37,41,42]$. Thewes [26] and colleagues investigated 73 adolescents and young adults (aged 18-35) and found 45 of them (62\%) reported high levels of FCR (CWS total score $\geq 14$ ). This finding is similar to Mattsson's study which reported 185 out of 286 (61\%) of young gynecological cancer survivors experienced FCR [37], but it is inconsistent with Wang's study which found that only 7\% of the AYAs reported strong worry about recurrence (rated as 'strongly agree') [42]. Another study with 292 survivors showed that about half of the participants experienced moderateto-high recurrence fear ( $2 \leq \mathrm{FCR}$ mean score $<3)$, but only $13 \%$ of them reported high level of FCR (mean score $=3$ ) [41]. Puukko et al. also suggested that around $52 \%$ of survivors experience FCR. However, a much higher figure (85.2\%) was reported in a large sample study of 1395 AYAs using a single FCR question derived from the Quality of Life in Adult Cancer Survivors Scale [25]. Only one study reported longitudinal outcomes of FCR prevalence, this study revealed that about $29 \%$ of AYA survivors reported FCR at study baseline, and the percentage slightly increased at one-year follow up (31\%), which indicated that FCR tended to remain stable in AYAs. Overall, across different cancer types and evaluation strategies, $29 \%$ to $85.2 \%$ of AYA survivors reported some degree of FCR [25, 30, 32, 37], 31\% to $49.1 \%$ reported moderate to high level of FCR $[41,42]$ and $13 \%$ to $62 \%$ reported high level of FCR $[26,42]$. 


\section{Determinants of FCR}

Potential determinants of FCR were classified into three groups (demographic, clinical/treatment, and psychological) according to conceptual similarity. In those studies where both univariate and multivariate analyses were employed, multivariate results were presented preferentially. In all, six studies investigated determinants related to FCR $[25,26$, $35,37,42,43]$.

Detailed factors associated with FCR in AYA cancer survivors were presented in Table 2. Thewes et al. [26] examined the relationship between a number of sociodemographic and clinical variables with levels of FCR. Results show that participant's age, gender, education, living situation, occupational status, cancer type, phase of treatment, and cancer stage were not significantly related to recurrence fears [26]. Mattsson et al. [37] investigated 337 gynecological cancer survivors and found that age at diagnosis, previous serious life events and have children or not did not have significant associations with FCR levels. However, multimodal treatment (such as surgery, and/or chemotherapy and/or radiotherapy) and a history of psychological distress significantly predicted cancer related distress, such as FCR. Inconsistent findings were reported by Shay and her colleagues. They found that FCR was associated with gender, employment and type of cancer. Survivors who were employed and less than 5 years from treatment were positively related to FCR, while thyroid cancer survivors, and those in clinical trial were less likely to report FCR [25].

Additionally, Lebel [35] concluded that younger age at diagnosis (less than 35) was associated with greater FCR than survivors in the other age categories. Wang et al. [42] revealed that female and higher treatment intensity were significantly associated with increased FCR. One study examined the relationship between spiritual distress and FCR in 120 mixed AYA cancer survivors and found that spiritual struggle was significant positively related to FCR in a bivariate correlation analysis. However, this association disappeared when having undergone chemotherapy was controlled [43].

\section{Consequences of FCR}

Eleven articles reported information about consequences of FCR [26, 30, 32-34, 36, 38-41, 44]. A study [31] found that FCR was the foremost intense life change the AYA survivors had 
experienced. Strong evidence has been found to support the relationship between high FCR and low Quality of Life [26, 33, 41]. Thewes et al. [26] found that adolescent and young adult cancer survivors who reported high FCR tended to report worse functioning in both psychological and social domains. Compared with survivors with low FCR, those who experienced higher FCR were also more likely to report higher anxiety levels, total psychological distress and lower overall health-related quality of life. However, no difference was found for depression, physical or religious functioning. Cho et al. [41] found that FCR was significant negatively associated with both mental and physical health related QoL. Additionally, the negative relationship between FCR and mental health-related QoL was moderated by perceived growth.

Poort and colleagues [44] examined the association between FCR and fatigue severity by the Cancer Worry Scale and Checklist Individual Strength (CIS-fatigue). Findings revealed that higher FCR was moderately correlated to fatigue severity [44]. Studies also found that FCR may lead to decreased breast self-examination frequency [32] and less nicotine dependence [40]. Compared to younger adolescents (aged 12-15), older adolescents (aged 16-18) are less likely to perform breast self-examination because of general fear about cancer and FCR.

In addition, FCR may also influence AYA survivor's attitude towards future pregnancy and parenting, one study showed that more than one third of the participants did not want to have additional children because of FCR [36]. However, other studies indicated that FCR did not significantly affect an individual's attitude towards self-image or life outlook, and Puukko et al. [30] indicated that FCR was not related to the frequency of somatic symptoms in AYA cancer survivors. Consequences of FCR in AYA cancer survivors are summarized in Table 3.

\section{Discussion}

Even though FCR study has expanded progressively over the last decade, there are only a few studies that focus specifically on FCR in AYA cancer survivors. To our best knowledge, at least three reviews of the literature have been conducted in AYAs to investigate their posttreatment outcomes, Quality of Life, as well as the influence of psychosocial interventions [45-47]. However, this is the first review to explore FCR in AYAs. It has been frequently reported that younger age is significantly associated with higher levels of FCR [17].

This article is protected by copyright. All rights reserved. 
Therefore, we believe it is of importance to systematically explore the prevalence, correlates and potential consequences of FCR in this special population group.

Of the 17 included articles, of which all, but one, received a strong overall quality rating, three concentrated specifically on breast cancer survivors, and one on leukemia. It has been found that the incidence of specific cancer types varies according to age [28]. For example, leukemia, lymphoma, testicular cancer, and thyroid cancer are the most common cancers among 15-24-year-olds, and among 25-39-year-olds, breast cancer and melanoma are the most common. Our review also found that all of the included studies were conducted in North America or European counties, which indicated that Asian countries have not provided sufficient attention on FCR in AYA survivors.

\section{Prevalence of FCR}

The prevalence data on FCR is inconsistent. Simard et al. [17] reported that around 39\% to $97 \%$ (on average $73 \%$ ) of adult cancer survivors reported some degree of FCR and $0 \%$ to $15 \%$ (on average $7 \%$ ) reported high degree. In the current review, we found $29 \%$ to $85.2 \%$ of AYA survivors reported some level of FCR, and $13 \%$ to $62 \%$ reported high level. The interpretation of the prevalence across studies is challenging as many studies utilized single question/unvalidated study-designed scales which provided limited psychometric evidence. In addition, no consensus is available about the definition of AYA or what constitutes clinical levels of FCR.

One study found that there was a slight increase in FCR over time in AYA cancer population. A recent study followed adult breast cancer patients soon after primary surgery and assessed FCR at baseline, 6 and 18 months follow up [48]. They reported that FCR was stable for the first 6 months but at 1.5 years increased in younger compared to older patients. Another study by Manne and colleagues [49] found that nearly $50 \%$ of the adult patients diagnosed with gynecological cancer continued to experience a high level of FCR (highstable) 6 months after cancer diagnosis, and about $25 \%$ of them reported decreasing FCR over time (high-decreasing) while the remaining $25 \%$ reported consistently low FCR (lowstable).

This article is protected by copyright. All rights reserved. 


\section{Determinants of FCR}

Most the demographic and clinical factors were found to be not significantly associated with levels of FCR in AYAs, but weak evidence emerged for gender, treatment intensity and psychological distress. Even though only two studies suggested that female experienced greater fear than male AYAs, this finding is consistent with several studies in adult cancer patients [13, 50-52]. However, many contrary findings were also reported. In Simard's review [17], a total of 12 studies found no relationship between gender and FCR in adults. In our current review, one study also reported a nonsignificant association [26]. Further research is needed to better understand the association between gender and FCR.

Our finding showed that different treatment type (i.e. surgery) was unrelated to FCR, but higher treatment intensity was significantly associated with increased FCR. Some previous studies identified radiotherapy/chemotherapy as predictors of higher FCR, however, this relationship tended to disappear in multivariate analyses $[53,54]$. One possible reason is that those who were more intensively treated may have greater awareness and more knowledge about risks for chronic health complications. Another reason may be the treatment-related symptoms/side effects, such as tiredness, nausea, and skin reaction caused by radiotherapy and chemotherapy. It has been found that physical and cognitive impairments through treatment side effects could greatly contribute to elevated FCR [55]. Higher treatment intensity and longer treatment duration might cause more side effects. Those symptoms might be viewed by the patients as a constant reminder of their disease, which further leads to increased FCR [18].

Regarding psychological factors, there are a number of existing studies [56-59] that have demonstrated a moderate positive correlation between FCR and generalized anxiety, hypochondriasis, as well as depression. In particular, a strong association between depression, symptom distress and elevated FCR in adult cancer survivors has been consistently identified $[23,60]$.

\section{Consequences of FCR}

Our review found that AYA cancer survivors with FCR were more likely to have impaired psychological functioning and overall health-related Quality of Life. As a common and 
persistent concern, FCR was consistently found to have a detrimental effect on patient's QoL $[61,62]$. Simard et al. also reported a strong negative association between FCR and QoL or functional domains (i.e. mental, role, social and cognitive functioning etc.) in adult cancer populations [17]. It is reasonable to assume that unexpected cancer diagnosis and treatment may present great challenges to AYAs and may also influence their choices in education, marriage, and occupational pursuits in the future, which further worsen their psychological distress and impair their QoL [45-47]. Researchers believe that alleviating this concern could considerably help to improve patient's life outcomes [62].

\section{Clinical Implications}

It is of importance to ensure AYAs receive sufficient information and help on dealing with FCR. To date, several organizations have developed detailed guidelines for AYA cancer populations to provide better psychological service [46]. However, specific FCR interventions for AYAs are still lacking. Therefore, providing more attention to AYA populations and developing more specific psychological programs for them is necessary. Researchers suggested that AYA-specific programs should consist of a multidisciplinary group with professional knowledge and skills [63]. Besides traditional counsellors, religious peers, support groups and clinical psychologists, in particular, the team should include a highly motivated person with a professional interest in AYA oncology/survivorship (an 'AYA champion') [63]. It is believed that with this 'champion' the multidisciplinary team would identify better the unique needs of AYAs. In addition, routines assessment for FCR during clinical follow-up appointments could also greatly help to identify the problem. Early identification could lead to early intervention and management, and consequently improve the patient's life outcomes.

This review also highlighted significant implications in the clinical research of FCR in AYAs. First, the instruments to adequately measure FCR in AYA cancer survivors are not satisfactory. All the existing FCR measurements were developed based on adult cancer populations. Hence some reassurance that these measures have good psychometric properties for AYAs would be beneficial. Second, there is a need for further investigation on FCR in more diverse samples, particularly in Asian AYA populations. Third, longitudinal studies that can monitor the change of FCR over time and to further identify causal 
associations are warranted. The majority of the FCR studies used cross-sectional designs, therefore, limited the examination of the development of FCR, and the dynamics of the relationship between FCR and psychosocial consequences. Better understanding of FCR in AYAs would be beneficial for developing AYA-specific programs in health care institutions.

\section{Study Limitations}

There are several limitations in this review that require consideration. First, the overall target sample is homogenous (all white, from north America or European countries). This may preclude generalization to other populations. Also, most of the included studies were crosssectional and the sample size varied significantly (ranged from 20 to 1395). Out of the seventeen included studies, ten of them were published after Simard's robust review in 2013 and seven were published recently within three years. However, there is still an overlap between the studies included in the current review and those in previous reviews. The number of scale items also varied widely and FCR was assessed using a range of measurements among the included studies, additionally, insufficient efforts have been made to establish standard clinical cut-offs of FCR. Finally, no attempt was made to search for nonEnglish articles or unpublished articles, and qualitative studies were excluded in the current review. Therefore, we suggest that these results should be interpreted with caution.

\section{Conclusion}

FCR is a prevalent concern among AYA population but it has not been adequately assessed or research advanced enough to establish design criteria for development of targeted interventions to manage FCR for this specialist group of patients. Longitudinal studies in AYAs are needed to examine further the long-term development and influence of FCR. Ageappropriate and flexible psychological care services are likely to be indicated from this more advanced information base, if initial speculation from this review is confirmed. Decreasing FCR may lead to improved Quality of Life and better adherence to cancer surveillance, therefore, increased attention should be targeted at AYA cancer survivors.

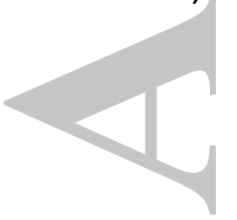

This article is protected by copyright. All rights reserved. 


\section{Acknowledgements}

We sincerely thank all the colleagues who we have discussed this manuscript with. We would also like to thank the President Foundation of Nanfang Hospital, Southern Medical University (2007L001) and the Science and technology project of Guangdong Province (2015A030302025) for funding the study.

\section{Compliance with Ethical Standards}

\section{Funding Information}

This study is funded by the President Foundation of Nanfang Hospital, Southern Medical University (2017L001); and the Science and technology project of Guangdong Province (2015A030302025)

\section{Conflict of interest}

Authors declare that they have no conflict of interest.

\section{Ethics Approval}

The Southern Medical University Nanfang Hospital Research Ethics Committee examined and approved the study (ref No: NFEC-2018-038)

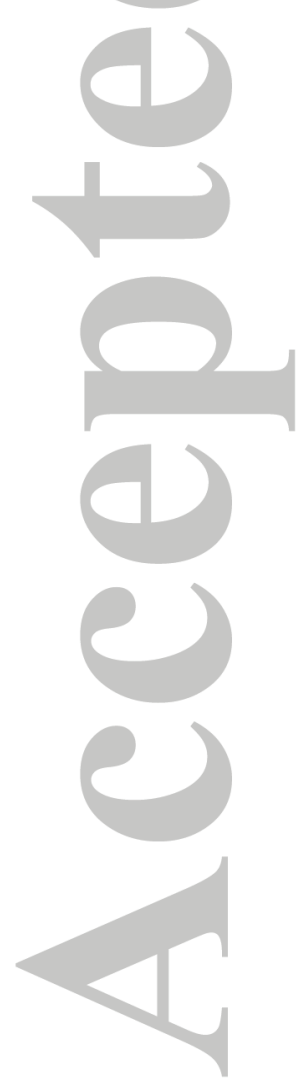




\section{Reference}

1. Lee-Jones, C., et al., Fear of cancer recurrence--a literature review and proposed cognitive formulation to explain exacerbation of recurrence fears. Psychooncology, 1997. 6(2): p. 95-105.

2. Herschbach, P. and A. Dinkel, Fear of progression. Recent Results Cancer Res, 2014. 197: p. 11-29.

3. Custers, J.A., et al., The Cancer Worry Scale: detecting fear of recurrence in breast cancer survivors. Cancer Nurs, 2014. 37(1): p. E44-50.

4. Koch, L., et al., Fear of recurrence and disease progression in long-term (>/= 5 years) cancer survivors-a systematic review of quantitative studies. Psychooncology, 2013. 22(1): p. 1-11.

5. Herschbach P, D.A., Fear of Progression. Psycho-Oncology (Recent Results in Cancer Research 197), ed. G. U. 2014, Berlin: Springer. 11-29.

6. Lebel, S., et al., From normal response to clinical problem: definition and clinical features of fear of cancer recurrence. Support Care Cancer, 2016. 24(8): p. 3265-8.

7. Lebel, S., et al., Does fear of cancer recurrence predict cancer survivors' health care use? Supportive Care in Cancer, 2013. 21(3): p. 901-906.

8. Otto, A.K., et al., Assessing the relationship between fear of cancer recurrence and health care utilization in early-stage breast cancer survivors. Journal of Cancer Survivorship, 2018. 12(6): p. 775-785.

9. Lasry, J.C. and R.G. Margolese, Fear of recurrence, breast-conserving surgery, and the trade-off hypothesis. Cancer, 1992. 69(8): p. 2111-5.

10. Simard, S., J. Savard, and H. Ivers, Fear of cancer recurrence: specific profiles and nature of intrusive thoughts. J Cancer Surviv, 2010. 4(4): p. 361-71.

11. Avis, N.E., et al., Assessing quality of life in adult cancer survivors (QLACS). Qual Life Res, 2005. 14(4): p. 1007-23.

12. Lebel, S., et al., Emotional distress impacts fear of the future among breast cancer survivors not the reverse. J Cancer Surviv, 2009. 3(2): p. 117-27.

13. Simard, S. and J. Savard, Fear of Cancer Recurrence Inventory: development and initial validation of a multidimensional measure of fear of cancer recurrence. Support Care Cancer, 2009. 17(3): p. 241-51.

14. Hartl, K., Impact of medical and demographic factors on long-term quality of life and body image of breast cancer patients. Annals of Oncology, 2003. 14(7): p. 1064-1071.

15. Hodgkinson, K., et al., The development and evaluation of a measure to assess cancer survivors' unmet supportive care needs: the CaSUN (Cancer Survivors' Unmet Needs measure). Psychooncology, 2007. 16(9): p. 796-804.

16. Hodgkinson, K., et al., Breast cancer survivors' supportive care needs 2-10 years after diagnosis. Support Care Cancer, 2007. 15(5): p. 515-23.

17. Simard, S., et al., Fear of cancer recurrence in adult cancer survivors: a systematic review of quantitative studies. J Cancer Surviv, 2013. 7(3): p. 300-22.

18. Yang, Y., J. Cameron, and G. Humphris, The relationship between cancer patient's fear of recurrence and radiotherapy: a systematic review and meta-analysis. Psychooncology, 2016.

19. Yang, Y., et al., The relationship between cancer patient's fear of recurrence and chemotherapy: $A$ systematic review and meta-analysis. J Psychosom Res, 2017. 98: p. 55-63.

20. Custers, J.A., et al., Towards an evidence-based model of fear of cancer recurrence for breast cancer survivors. J Cancer Surviv, 2017. 11(1): p. 41-47.

21. Smith, A., et al., Medical, demographic and psychological correlates of fear of cancer recurrence (FCR) morbidity in breast, colorectal and melanoma cancer survivors with probable clinically significant FCR seeking psychological treatment through the ConquerFear study. Support Care Cancer, 2018.

This article is protected by copyright. All rights reserved. 
22. Yang, Y., et al., Factors associated with fear of progression in chinese cancer patients: sociodemographic, clinical and psychological variables. Journal of Psychosomatic Research, 2018. 114: p. 18-24.

23. Crist, J.V. and E.A. Grunfeld, Factors reported to influence fear of recurrence in cancer patients: a systematic review. Psychooncology, 2013. 22(5): p. 978-86.

24. Ozga, M., et al., A systematic review of ovarian cancer and fear of recurrence. Palliat Support Care, 2015. 13(6): p. 1771-80.

25. Shay, L.A., M.Y. Carpentier, and S.W. Vernon, Prevalence and correlates of fear of recurrence among adolescent and young adult versus older adult post-treatment cancer survivors. Supportive Care In Cancer: Official Journal Of The Multinational Association Of Supportive Care In Cancer, 2016. 24(11): p. 4689-4696.

26. Thewes, B., et al., Prevalence and correlates of high fear of cancer recurrence in late adolescents and young adults consulting a specialist adolescent and young adult (AYA) cancer service. Support Care Cancer, 2018. 26(5): p. 1479-1487.

27. WHO. Adolescent health. 2018 [cited 201820 Oct]; Available from: https://www.who.int/topics/adolescent health/en/.

28. NIH. National Cancer Institute: Adolescents and Young Adults with Cancer. 2018 [cited 201820 Sep]; Available from: https://www.cancer.gov/types/aya.

29. Kmet LML, L.R., Cook, LS. . Standard quality assessment criteria for evaluating primary research papers from $a$ variety of fields. 2004 [cited 201820 Sep]; Available from: https://era.library.ualberta.ca/items/48b9b989-c221-4df6-9e35-af782082280e.

30. Puukko, L.R., et al., Young female survivors of childhood leukaemia do not have increased somatic concerns. Acta Paediatrica (Oslo, Norway: 1992), 1998. 87(2): p. 169-174.

31. Roberts, C.S., et al., Life changes and problems experienced by young adults with cancer. Journal of Psychosocial Oncology, 1997. 15(1): p. 15-25.

32. Cox, C.L., et al., Supporting breast self-examination in female childhood cancer survivors: a secondary analysis of a behavioral intervention. Oncology Nursing Forum, 2008. 35(3): p. 423-430.

33. Zebrack, B.J. and M. Chesler, Health-related worries, self-image, and life outlooks of long-term survivors of childhood cancer. Health \& Social Work, 2001. 26(4): p. 245-256.

34. Zebrack, B.J. and M.A. Chesler, Quality of life in childhood cancer survivors. Psycho-Oncology, 2002. 11(2): p. 132-141.

35. Lebel, S., et al., Young and worried: Age and fear of recurrence in breast cancer survivors. Health Psychol, 2013. 32(6): p. 695-705.

36. Senkus, E., et al., Attitudes of young patients with breast cancer toward fertility loss related to adjuvant systemic therapies. EORTC study 10002 BIG 3-98. Psychooncology, 2014. 23(2): p. 173-82.

37. Mattsson, E., et al., Women treated for gynaecological cancer during young adulthood - A mixedmethods study of perceived psychological distress and experiences of support from health care following end-of-treatment. Gynecol Oncol, 2018. 149(3): p. 464-469.

38. Kremer, A.-L., et al., Long-term positive and negative psychosocial outcomes in young childhood cancer survivors, type 1 diabetics and their healthy peers. International Journal Of Adolescent Medicine And Health, 2016. 29(6).

39. Seitz, D.C., et al., Efficacy of an internet-based cognitive-behavioral intervention for long-term survivors of pediatric cancer: a pilot study. Support Care Cancer, 2014. 22(8): p. 2075-83.

40. de Moor, J.S., et al., Disseminating a smoking cessation intervention to childhood and young adult cancer survivors: baseline characteristics and study design of the partnership for health-2 study. BMC Cancer, 
2011. 11: p. 165-165.

41. Cho, D. and C.L. Park, Moderating effects of perceived growth on the association between fear of cancer recurrence and health-related quality of life among adolescent and young adult cancer survivors. J Psychosoc Oncol, 2017. 35(2): p. 148-165.

42. Wang, R., et al., Exploring Cancer Worry in Adolescent and Young Adult Survivors of Childhood Cancers. J Adolesc Young Adult Oncol, 2015. 4(4): p. 192-9.

43. Park, C.L. and D. Cho, Spiritual well-being and spiritual distress predict adjustment in adolescent and young adult cancer survivors. Psycho-Oncology, 2017. 26(9): p. 1293-1300.

44. Poort, H., et al., Prevalence and impact of severe fatigue in adolescent and young adult cancer patients in comparison with population-based controls. Support Care Cancer, 2017. 25(9): p. 2911-2918.

45. Barnett, M., et al., Psychosocial outcomes and interventions among cancer survivors diagnosed during adolescence and young adulthood (AYA): a systematic review. J Cancer Surviv, 2016. 10(5): p. 814-31.

46. Quinn, G.P., et al., Quality of life in adolescent and young adult cancer patients: a systematic review of the literature. Patient Relat Outcome Meas, 2015. 6: p. 19-51.

47. Richter, D., et al., Psychosocial interventions for adolescents and young adult cancer patients: $A$ systematic review and meta-analysis. Crit Rev Oncol Hematol, 2015. 95(3): p. 370-86.

48. Starreveld, D.E.J., et al., The course of fear of cancer recurrence: Different patterns by age in breast cancer survivors. Psychooncology, 2017.

49. Manne, S.L., et al., Group-based trajectory modeling of fear of disease recurrence among women recently diagnosed with gynecological cancers. Psychooncology, 2016.

50. Baker, F., et al., Adult cancer survivors: how are they faring? Cancer, 2005. 104(11 Suppl): p. 2565-76.

51. Essers, B.A., et al., Determinants of satisfaction with the health state of the facial skin in patients undergoing surgery for facial basal cell carcinoma. Patient Educ Couns, 2006. 60(2): p. 179-86.

52. Gemmill, R., et al., Going with the flow: quality-of-life outcomes of cancer survivors with urinary diversion. J Wound Ostomy Continence Nurs, 2010. 37(1): p. 65-72.

53. Hong, Y.M., et al., Impact of radical prostatectomy positive surgical margins on fear of cancer recurrence: results from CaPSURE. Urol Oncol, 2010. 28(3): p. 268-73.

54. Janz, N.K., et al., Correlates of worry about recurrence in a multiethnic population-based sample of women with breast cancer. Cancer, 2011. 117(9): p. 1827-36.

55. Mehnert, A., et al., Fear of cancer progression and cancer-related intrusive cognitions in breast cancer survivors. Psychooncology, 2009. 18(12): p. 1273-80.

56. Chaturvedi, S.K., et al., Concerns, coping and quality of life in head and neck cancer patients. Support Care Cancer, 1996. 4(3): p. 186-90.

57. Humphris, G.M., et al., Fear of recurrence and possible cases of anxiety and depression in orofacial cancer patients. Int J Oral Maxillofac Surg, 2003. 32(5): p. 486-91.

58. Llewellyn, C.D., et al., Can we predict which head and neck cancer survivors develop fears of recurrence? J Psychosom Res, 2008. 65(6): p. 525-32.

59. Thewes, B., et al., Psychological morbidity and stress but not social factors influence level of fear of cancer recurrence in young women with early breast cancer: results of a cross-sectional study. Psychooncology, 2013. 22(12): p. 2797-806.

60. Pedersen, A.F., et al., Fear of recurrence and causal attributions in long-term survivors of testicular cancer. Psychooncology, 2012. 21(11): p. 1222-8.

61. Hedman, C., et al., Fear of Recurrence and View of Life Affect Health-Related Quality of Life in Patients with Differentiated Thyroid Carcinoma: A Prospective Swedish Population-Based Study. Thyroid, 2018. 
62. Rogers, S.N., et al., Health-related quality of life, fear of recurrence, and emotional distress in patients treated for thyroid cancer. Br J Oral Maxillofac Surg, 2017. 55(7): p. 666-673.

63. Reed, D., R.G. Block, and R. Johnson, Creating an adolescent and young adult cancer program: lessons learned from pediatric and adult oncology practice bases. J Natl Compr Canc Netw, 2014. 12(10): p. 1409-15.

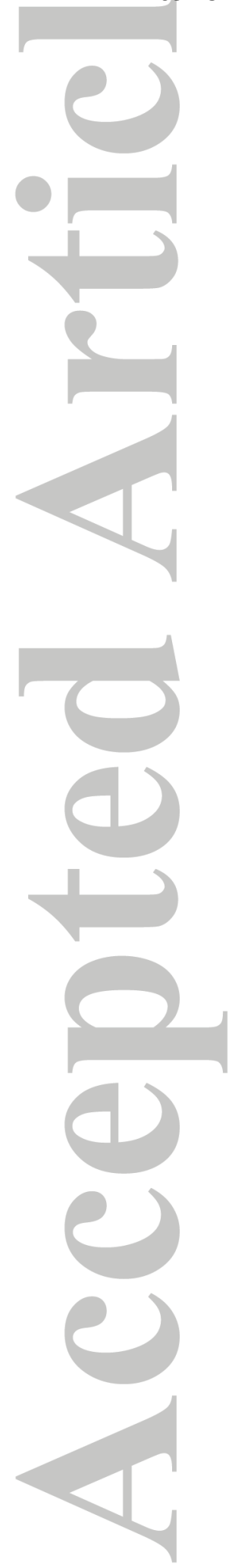

This article is protected by copyright. All rights reserved. 
Figure 1. PRISMA flowchart

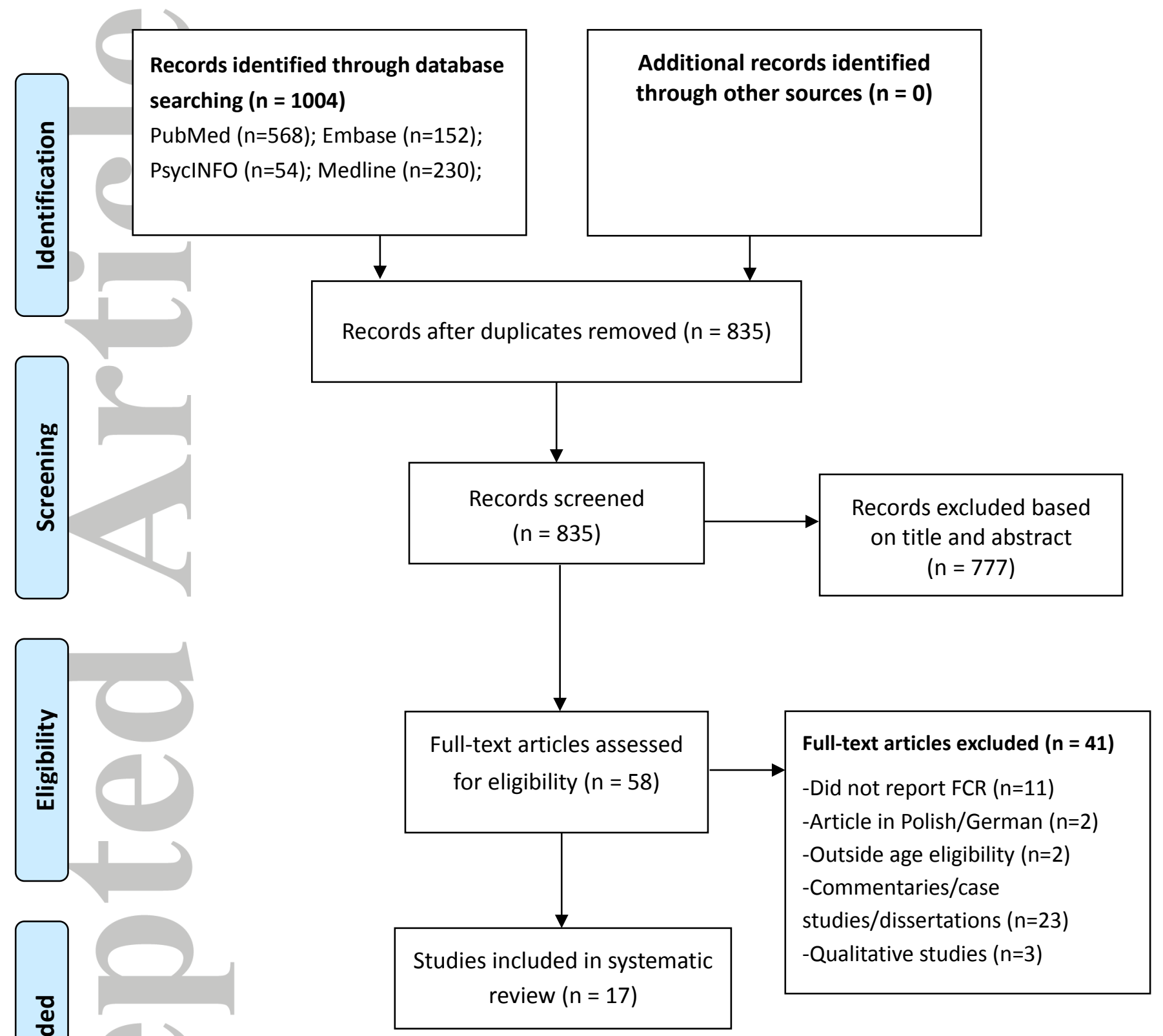

This article is protected by copyright. All rights reserved. 
Table 1 Characteristics of included studies

\begin{tabular}{|c|c|c|c|c|c|c|c|c|}
\hline $\begin{array}{l}\text {-Author } \\
\text {-Year }\end{array}$ & Country & Study Design & $\begin{array}{l}\text { Cance } \\
\text { r Type }\end{array}$ & $\begin{array}{l}\text { N } \\
\text { (female \%) }\end{array}$ & $\begin{array}{l}\text {-Age at } \\
\text { Diagnosis } \\
\text {-Age at Survey } \\
\text { Mean (SD) }{ }^{a}\end{array}$ & $\begin{array}{l}\text { Time since } \\
\text { Diagnosis } \\
\text { Mean (SD) }\end{array}$ & Instrument & $\begin{array}{l}\text { Main finding (FCR Prevalence, } \\
\text { Determinants, and consequence) }\end{array}$ \\
\hline $\begin{array}{l}\text {-Thewes } \\
{[26]} \\
-2018\end{array}$ & $\begin{array}{l}\text { Netherland } \\
\text { s }\end{array}$ & $\begin{array}{l}\text { Cross- } \\
\text { sectional }\end{array}$ & Mix & 73 (51\%) & $\begin{array}{l}-27.4(4.6), \\
\text { range from } 18 \text { to } \\
35 \\
-N R\end{array}$ & $1.9(2.6)$ & CWS & $\begin{array}{l}\text {-Prevalence: } 62 \% \text { reported high FCR } \\
\text {-Determinants: sociodemographic and } \\
\text { clinical variables were not significantly } \\
\text { associated with levels of FCR } \\
\text {-Consequence: High FCR was associated } \\
\text { with lower psychological, social } \\
\text { functioning and overall QoL }(P<0.01)\end{array}$ \\
\hline $\begin{array}{l}- \text { Mattsson } \\
-2018[37]\end{array}$ & Sweden & $\begin{array}{l}\text { Cross- } \\
\text { sectional }\end{array}$ & $\begin{array}{l}\text { gynec } \\
\text { ologic } \\
\text { al }\end{array}$ & $\begin{array}{l}337 \\
(100 \%)\end{array}$ & $\begin{array}{l}-32.6(4.9), \\
\text { range from } 19 \text { to } \\
39 \\
-36.9(5.1)\end{array}$ & 2.9 (1.9) & $\begin{array}{l}\text { Study- } \\
\text { specific } \\
\text { questionnair } \\
\text { e }\end{array}$ & $\begin{array}{l}\text {-Prevalence: } 61 \% \text { reported FCR } \\
\text {-Determinants: multimodal treatment } \\
\text { (OR=2.25) and a history of } \\
\text { psychological distress (OR=3.44) } \\
\text { predicted cancer related distress } \\
\text { (including FCR) }\end{array}$ \\
\hline $\begin{array}{l}\text {-Poort } \\
-2017[44]\end{array}$ & $\begin{array}{l}\text { Netherland } \\
\mathrm{s}\end{array}$ & $\begin{array}{l}\text { Cross- } \\
\text { sectional }\end{array}$ & Mix & $83(48 \%)$ & $\begin{array}{l}-27.3(4.4), \\
\text { range from } 18 \text { to } \\
35 \\
-29.4(4.7)\end{array}$ & $2.1(2.6)$ & CWS & $\begin{array}{l}\text {-Consequence: higher FCR was } \\
\text { moderate correlated with severe } \\
\text { fatigue ( } r^{\prime} \text { s: } 0.30-0.50, P<0.01 \text { ) }\end{array}$ \\
\hline $\begin{array}{l}- \text { Park [43] } \\
-2017\end{array}$ & US & $\begin{array}{l}\text { Cross- } \\
\text { sectional }+ \\
\text { follow up }\end{array}$ & Mix & $\begin{array}{l}120 \\
(77.9 \%)\end{array}$ & $\begin{array}{l}-28.9(6.8), \\
\text { range from } 15 \text { to } \\
39 \\
-32.6(7.4)\end{array}$ & $3.8(3.0)$ & CARS & $\begin{array}{l}\text {-Determinants: spiritual struggle was } \\
\text { positively associated with FCR }(r=0.24 \text {, } \\
P=0.04)\end{array}$ \\
\hline $\begin{array}{l}- \text { Cho }[41] \\
-2017\end{array}$ & US & $\begin{array}{l}\text { Cross- } \\
\text { sectional }\end{array}$ & Mix & $\begin{array}{l}292 \\
(80.5 \%)\end{array}$ & $\begin{array}{l}\text {-range } 15-34 \\
-33.3(7.1)\end{array}$ & $3.8(2.5)$ & ASC & $\begin{array}{l}\text {-Prevalence: } 49.1 \% \text { reported moderate- } \\
\text { to- high FCR, } 13 \% \text { reported high FCR } \\
\text {-Consequence: FCR was negatively } \\
\text { related to both physical }(P=0.01) \text { and } \\
\text { mental health-related QoL }(P<0.001)\end{array}$ \\
\hline $\begin{array}{l}- \text { Shay [25] } \\
-2016\end{array}$ & US & $\begin{array}{l}\text { Cross- } \\
\text { sectional }\end{array}$ & Mix & $\begin{array}{l}1395 \\
(59.7 \%)\end{array}$ & $\begin{array}{l}-30.0(6.6), \\
\text { range from } 15 \text { to } \\
39\end{array}$ & NR & $\begin{array}{l}\text { Single item } \\
\text { from the QoL } \\
\text { in Adult }\end{array}$ & $\begin{array}{l}\text {-Prevalence: } 85.2 \% \text { reported FCR } \\
\text {-Determinants: being employed, less } \\
\text { than } 5 y \text { rs off treatment were positively }\end{array}$ \\
\hline
\end{tabular}

This article is protected by copyright. All rights reserved. 


\begin{tabular}{|c|c|c|c|c|c|c|c|c|}
\hline & & & & & $\begin{array}{l}-38 \text { (range 18- } \\
73)\end{array}$ & & $\begin{array}{l}\text { Cancer } \\
\text { Survivors } \\
\text { Scale }\end{array}$ & $\begin{array}{l}\text { related to FCR; thyroid cancer patients, } \\
\text { and those in clinical trial were less likely } \\
\text { to report FCR }\end{array}$ \\
\hline $\begin{array}{l}\text {-Kremer } \\
{[38]} \\
-2016\end{array}$ & Germany & $\begin{array}{l}\text { Cross- } \\
\text { sectional }\end{array}$ & NR & $33(45.5 \%)$ & $\begin{array}{l}-8.1(5.1) \text {, range } \\
\text { from } 0 \text { to } 18 \\
-23.8(3.8), \\
\text { range from } 18 \text { to } \\
34\end{array}$ & NR & $\begin{array}{l}\text { Fear of } \\
\text { disease } \\
\text { Progression } \\
\text { questionnair } \\
\text { e-short form }\end{array}$ & $\begin{array}{l}\text {-Consequence: posttraumatic growth } \\
\text { was experienced by AYAs, FCR reported } \\
\text { by Childhood cancer survivors was } \\
\text { lower than AYA patients with type } 1 \\
\text { diabetics ( } P<0.001)\end{array}$ \\
\hline $\begin{array}{l}- \text { Wang [42] } \\
-2015\end{array}$ & Canada & $\begin{array}{l}\text { Cross- } \\
\text { sectional }\end{array}$ & Mix & 250 (46\%) & $\begin{array}{l}\text {-range } 0-17 \\
\text {-range } 15-26\end{array}$ & NR & 6-item CWS & $\begin{array}{l}\text {-Prevalence: } 7 \% \text { strongly worry about } \\
\text { relapse and 31\% reported moderate } \\
\text { FCR } \\
\text {-Determinants: female and higher } \\
\text { treatment intensity were associated } \\
\text { with higher cancer worry }\end{array}$ \\
\hline $\begin{array}{l}\text {-Senkus } \\
-2014[36]\end{array}$ & US & $\begin{array}{l}\text { Cross- } \\
\text { sectional }\end{array}$ & Breast & $\begin{array}{l}389 \\
(100 \%)\end{array}$ & $\begin{array}{l}- \text { aged }<36 \\
-N R\end{array}$ & 0.5 (NR) & $\begin{array}{l}\text { Interview } \\
\text { question }\end{array}$ & $\begin{array}{l}\text {-Consequence: } 36 \% \text { survivors who did } \\
\text { not want additional children because of } \\
\text { FCR }\end{array}$ \\
\hline $\begin{array}{l}\text {-Seitz [39] } \\
-2014\end{array}$ & Germany & $\begin{array}{l}\text { Cross- } \\
\text { sectional }+ \\
\text { follow up }\end{array}$ & Mix & $20(70 \%)$ & $\begin{array}{l}-N R \\
-27.3(4.8), \\
\text { range from } 20 \text { to } \\
36\end{array}$ & $13.8(4.7)$ & FoP-SF & $\begin{array}{l}\text {-Consequence: } 45 \% \text { of the survivors } \\
\text { showed an improvement on FCR after } \\
\text { an internet-based CBT intervention } \\
(P=0.031)\end{array}$ \\
\hline $\begin{array}{l}\text {-Lebel [35] } \\
-2013\end{array}$ & Canada & $\begin{array}{l}\text { Cross- } \\
\text { sectional }\end{array}$ & Breast & $\begin{array}{l}100 \\
(100 \%)\end{array}$ & $\begin{array}{l}-\mathrm{NR} \\
- \text { aged }<35\end{array}$ & 2.87 (3.94) & CARS & $\begin{array}{l}\text {-Determinants: younger age at } \\
\text { diagnosis }(<35) \text { was associated with } \\
\text { increased FCR than women in the other } \\
\text { age categories }\end{array}$ \\
\hline $\begin{array}{l}\text {-de Moor } \\
-2011[40]\end{array}$ & US & $\begin{array}{l}\text { Cross- } \\
\text { sectional }\end{array}$ & Mix & 374 (49\%) & $\begin{array}{l}\text {-aged }<35 \\
-32.4(7.94) \\
\text { range from } 18 \\
\text { to } 55\end{array}$ & $20(9.61)$ & $\begin{array}{l}\text { Single } \\
\text { question } \\
\text { from IES }\end{array}$ & $\begin{array}{l}\text {-Consequence: survivors who did not } \\
\text { have FCR were more likely to be } \\
\text { nicotine dependent (OR=2.08, } 95 \% \mathrm{Cl} \text { : } \\
0.81,5.32 \text { ) }\end{array}$ \\
\hline $\begin{array}{l}- \text { Cox [32] } \\
-2008\end{array}$ & US & $\begin{array}{l}\text { Cross- } \\
\text { sectional + } \\
\text { follow up }\end{array}$ & Breast & $\begin{array}{l}149 \\
(100 \%)\end{array}$ & $\begin{array}{l}-\mathrm{NR} \\
- \text { median=15, } \\
\text { range from 12- } \\
19\end{array}$ & $\begin{array}{l}\text { Median=11. } \\
72, \text { range } \\
2.23-16.89\end{array}$ & Single item & $\begin{array}{l}\text {-Prevalence: } 29 \% \text { reported FCR at } \\
\text { baseline, and } 31 \% \text { reported FCR one } \\
\text { year later } \\
\text {-Consequence: FCR predicted } \\
\text { decreased breast self-examination }\end{array}$ \\
\hline
\end{tabular}

This article is protected by copyright. All rights reserved. 


\begin{tabular}{|c|c|c|c|c|c|c|c|c|c|}
\hline & & & & & & & & & frequency \\
\hline & $\begin{array}{l}\text {-Zebrack } \\
-2002[34]\end{array}$ & US & $\begin{array}{l}\text { Cross- } \\
\text { sectional }\end{array}$ & Mix & $\begin{array}{l}176 \\
(57.4 \%)\end{array}$ & $\begin{array}{l}-8.5(5.1), \text { range } \\
\text { from } 0 \text { to } 22 \\
-21.8(3.3), \\
\text { range from } 16 \text { to } \\
28\end{array}$ & $13.3(5.7)$ & $\begin{array}{l}\text { Items from } \\
\text { Quality of } \\
\text { life-cancer } \\
\text { survivors }\end{array}$ & $\begin{array}{l}\text {-Consequence: FCR was associated with } \\
\text { low overall quality of life in AYAs } \\
(r=0.745)\end{array}$ \\
\hline & $\begin{array}{l}\text {-Zebrack } \\
\text {-2001 [33] }\end{array}$ & US & $\begin{array}{l}\text { Cross- } \\
\text { sectional }\end{array}$ & Mix & 303 (53\%) & $\begin{array}{l}-8.6(5.18), \\
\text { range from } 0 \text { to } \\
22 \\
-20.0(3.39), \\
\text { range from } 14 \text { to } \\
29\end{array}$ & $11.3(5.76)$ & $\begin{array}{l}\text { Self-designed } \\
\text { items }\end{array}$ & $\begin{array}{l}\text {-Consequence: cancer specific worry } \\
\text { (including FCR) did not significantly } \\
\text { predict survivors' self-image or life } \\
\text { outlook. }\end{array}$ \\
\hline & $\begin{array}{l}- \text { Puukko } \\
-1998[30]\end{array}$ & Finland & $\begin{array}{l}\text { Cross- } \\
\text { sectional }\end{array}$ & $\begin{array}{l}\text { leuke } \\
\text { mia }\end{array}$ & 42 (100\%) & $\begin{array}{l}-7.4(3.4) \\
-18.6(3.9)\end{array}$ & NR & $\begin{array}{l}\text { Two } \\
\text { questions }\end{array}$ & $\begin{array}{l}\text {-Prevalence: } 52 \% \text { reported FCR } \\
\text {-Consequence: FCR was unrelated to } \\
\text { frequency of somatic symptoms }\end{array}$ \\
\hline & $\begin{array}{l}\text {-Roberts } \\
-1997 \text { [31] }\end{array}$ & US & $\begin{array}{l}\text { Cross- } \\
\text { sectional }\end{array}$ & Mix & 46 (NR) & $\begin{array}{l}-\mathrm{NR} \\
-31.4(4.0), \\
\text { range from } 22 \text { to } \\
35\end{array}$ & $4.3(2.7)$ & Single item & $\begin{array}{l}\text {-Consequence: FCR was the most } \\
\text { intense life changes the survivors had } \\
\text { experienced (degree of change }=6.78 \text { ) }\end{array}$ \\
\hline
\end{tabular}

a mean (SD) in years; Abbreviation: NR: Not Report; FCR: Fear of Cancer Recurrence; QoL: Quality of Life; CWS: Cancer Worry Scale; CARS: Concerns About Recurrence Scale; ASC: Assessment of Survivor Concerns; FoP-SF: Fear of Progression Questionnaire-short form; IES: Impact of Event Scale 


\begin{tabular}{|c|c|c|c|}
\hline Factors & Nil & Positive association & Negative association \\
\hline \multicolumn{4}{|l|}{ Demographic } \\
\hline Gender (Female) & {$[26]^{\mathrm{a}}$} & {$[25]^{b},[42]^{b}$} & \\
\hline Age at survey (years) & & & {$[25]^{b}$} \\
\hline Race (white/other) & {$[25]^{\mathrm{a}},[42]^{\mathrm{a}}$} & & \\
\hline Employment (Yes/No) & {$[26]^{\mathrm{a}}$} & {$[25]^{b}$} & \\
\hline Education level & {$[25]^{\mathrm{a}},[26]^{\mathrm{a}},[42]^{\mathrm{a}}$} & & \\
\hline Married/Partnered & {$[25]^{b},[26]^{a}$} & & \\
\hline Have children (Yes/No) & {$[26]^{\mathrm{a}},[37]^{\mathrm{b}}$} & & \\
\hline Living situation & {$[26]^{\mathrm{a}}$} & & \\
\hline Total household income & {$[25]^{\mathrm{a}}$} & & \\
\hline Insurance status & {$[25]^{a}$} & & \\
\hline \multicolumn{4}{|l|}{ Clinical/Treatment } \\
\hline Age at diagnosis (Years) & {$[26]^{\mathrm{a}}$} & & {$[35]^{\mathrm{a}},[37]^{\mathrm{b}}$} \\
\hline Time since diagnosis (Years) & {$[26]^{a},[42]^{a}$} & & \\
\hline Cancer type & {$[26]^{\mathrm{a}},[42]^{\mathrm{b}}$} & & \\
\hline Cancer stage & {$[26]^{a}$} & & \\
\hline Treatment status (On/off) & {$[26]^{a}$} & & \\
\hline Surgery (Yes/No) & {$[25]^{b},[26]^{a}$} & & \\
\hline Radiotherapy (Yes/No) & {$[25]^{b},[26]^{a}$} & & \\
\hline Chemotherapy (Yes/No) & {$[26]^{a}$} & {$[43]^{b}$} & \\
\hline Hormonal therapy (Yes/No) & {$[26]^{\mathrm{a}}$} & & \\
\hline Immunotherapy (Yes/No) & & {$[26]^{a}$} & \\
\hline Number of treatment(s) & & {$[37]^{b},[42]^{b}$} & \\
\hline Less than 5 yrs off treatment & & {$[25]^{b}$} & \\
\hline Thyroid cancer & & & {$[25]^{b}$} \\
\hline In clinical trail & & & {$[25]^{b}$} \\
\hline Currently seeing a doctor & {$[25]^{\mathrm{b}}$} & & \\
\hline Relapse status (Yes/No) & {$[42]^{\mathrm{a}}$} & & \\
\hline \multicolumn{4}{|l|}{ Psychological } \\
\hline Anxiety & & {$[26]^{\mathrm{ac}}$} & \\
\hline Depression & {$[26]^{\mathrm{ac}}$} & & \\
\hline Psychological distress & & {$[26]^{\mathrm{ac}}$} & \\
\hline Past psychological distress & & {$[37]^{b}$} & \\
\hline Previous serious life events & {$[37]^{\mathrm{b}}$} & & \\
\hline Spiritual struggle & & {$[43]^{d}$} & \\
\hline
\end{tabular}

a Mean or frequency comparison analysis, ${ }^{\mathrm{b}}$ Multivariate regression model analysis, ${ }^{\mathrm{C}}$ Clinically relevant difference, ${ }^{\mathrm{d}}$ Correlations, AYA: adolescent and young adult 
Table 3 Consequences of FCR in AYA cancer survivors

\begin{tabular}{|c|c|c|c|}
\hline Consequences & Nil & Positive association & Negative association \\
\hline \multicolumn{4}{|l|}{ Quality of Life } \\
\hline Physical functioning & {$[26]^{\mathrm{ac}}$} & & {$[41]^{d}$} \\
\hline Psychological functioning & & & {$[26]^{\mathrm{ac}},[41]^{\mathrm{d}}$} \\
\hline Social functioning & & & {$[26]^{\mathrm{ac}}$} \\
\hline Religious functioning & {$[26]^{\mathrm{ac}}$} & & \\
\hline Overall health-related QoL & & & {$[26]^{\mathrm{ac}},[34]^{\mathrm{d}}$} \\
\hline \multicolumn{4}{|l|}{ Other outcomes } \\
\hline Nicotine dependent (Yes/No) & & & {$[40]^{\mathrm{b}}$} \\
\hline Breast self-examination & & & {$[32]^{\mathrm{a}}$} \\
\hline Somatic symptoms frequency & {$[30]^{d}$} & & \\
\hline Have additional children & & & {$[36]$} \\
\hline Fatigue severity & & {$[44]^{d}$} & \\
\hline Self-image & {$[33]^{\mathrm{b}}$} & & \\
\hline Life outlook & {$[33]^{b}$} & & \\
\hline
\end{tabular}

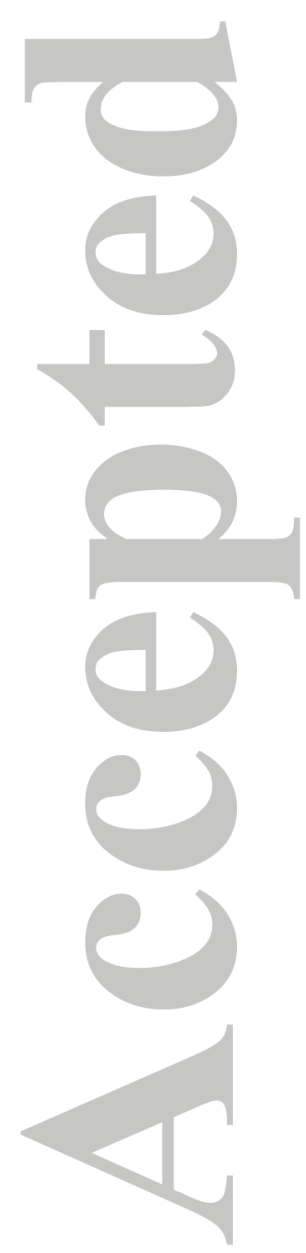

This article is protected by copyright. All rights reserved. 